\title{
Safety of probiotics and synbiotics in children under 18 years of age
}

\author{
M. van den Nieuwboer ${ }^{1}$, R.J. Brummer ${ }^{2}$, F. Guarner ${ }^{3}$, L. Morelli ${ }^{4}$, M. Cabana ${ }^{5}$ and E. Claassen $^{1,6^{*}}$ \\ ${ }^{1}$ VU University Amsterdam, Athena Institute, De Boelelaan 1085, 1081 HV Amsterdam, the Netherlands; ${ }^{2}$ School of Health \\ and Medical Sciences, Örebro University, 70182 Örebro, Sweden; ${ }^{3}$ Digestive System Research Unit, CIBERehd, University \\ Hospital Vall d'Hebron, 08035 Barcelona, Spain; ${ }^{4}$ Istituto di Microbiologia, Università Cattolica S.C., Via Emilia Parmense \\ 84, 29122 Piacenza, Italy; ${ }^{5}$ University of California San Francisco (UCSF), Departments of Pediatrics, Epidemiology and \\ Biostatistics, 3333 California Street, \#245, San Francisco, CA 94118, USA; ${ }^{6}$ Erasmus Medical Center, Department of \\ Viroscience, P.O. Box 2040, 3000 CA Rotterdam, the Netherlands; prof.eric.claassen@gmail.com
}

Received: 7 November 2014 / Accepted: 19 January 2015

(c) 2015 Wageningen Academic Publishers

RESEARCH ARTICLE

\begin{abstract}
This study aimed to systematically evaluate safety of probiotics and synbiotics in children ageing 0-18 years. This study is the third and final part in a safety trilogy and an update is provided using the most recent available clinical data (2008-2013) by means of the Common Terminology Clinical Adverse Events (CTCAE version 4.0) classification. Safety aspects are represented and related to number of participants per probiotic strain/culture, study duration, dosage, clinical condition and selected afflictions. Analysis of 74 clinical studies indicated that probiotic and/or synbiotic administration in children is safe with regard to the specific evaluated strains, dosages and duration. The population of children include healthy, immune compromised and obese subjects, as well as subjects with intestinal disorders, infections and inflammatory disorders. This study revealed no major safety concerns, as the adverse events (AEs) were unrelated, or not suspected to be related, to the probiotic or synbiotic product. In general the study products were well tolerated. Overall, AEs occurred more frequent in the control arm compared to children receiving probiotics and/or synbiotics. Furthermore, the results indicate inadequate reporting and classification of AEs in the majority of the studies. In addition, generalizability of conclusions are greatly limited by the inconsistent, imprecise and potentially incomplete reporting as well as the variation in probiotic strains, dosages, administration regimes, study populations and reported outcomes.
\end{abstract}

Keywords: probiotics, synbiotics, children, safety, prebiotics

\section{Introduction}

The human gut microbiota is of major importance in metabolic and physiological processes (Vyas and Ragnanathan, 2012). Additionally, the microbiota is proposed to play a key role in development, maturation and maintenance of the immune system (Alonso and Guarner, 2013; Buccigrossi et al., 2013; Kamada et al., 2013). Indeed, when individuals fail to acquire a 'normal' microbiota it is associated with illnesses and other complications (Buccigrossi et al., 2013; Hickey et al., 2012). For instance, the increasing prevalence of allergies in the developed world could be partially explained by the 'hygiene hypothesis' (Strachan, 1989). This hypothesis postulates that improved hygiene, healthcare and smaller families leads to a decrease in antigen exposure, including bacteria and fungi, thereby affecting immune development of infants and children (Van der Aa et al., 2010). The lack of bacterial exposure skews the immune response to a more IgE-mediated $\mathrm{T}_{\mathrm{H}}$ 2-response, which is associated with allergies and other pathologies. The early microbial colonisation is not only important in polarising the appropriate $\mathrm{T}_{\mathrm{H}} 1 / \mathrm{T}_{\mathrm{H}} 2$ balance; it is also suggested to play a role in regulatory mechanisms (Pan et al., 2010). This colonisation by microorganisms recognised as harmless by the immune system, also called 'old friends', drive regulatory T-cell polarisation and thereby down regulate auto- and allergic-immune responses (Guarner et al., 2006). Indeed, insufficient exposure to these 'old friends' might lead to a dysfunctional immune regulation. For instance, the risk of asthma is inversely related to the 
variety of microbial exposure (Ege et al., 2011). Children living in rural areas had a lower prevalence of asthma and atopy compared to children living in suburban areas (Ege et al., 2011). In addition to the autoimmune regulation, a shift from $\mathrm{T}_{\mathrm{H}} 1$ to $\mathrm{T}_{\mathrm{H}} 2$ cells renders individuals more susceptible to infections (Tan et al., 2011).

A possible therapeutic measure to modulate the aberrant gut composition is by supplementation of probiotics. Probiotics are defined as 'live microorganisms that, when administered in adequate amounts, confer a health benefit on the host' (Hill et al., 2014). Probiotics are often supplemented with prebiotics, which are 'non-viable food components that confer a health benefit on the host associated with modulation of the microbiota' (Piniero et al., 2008). Probiotics and prebiotics combined are defined as synbiotics. Although some mechanism of probiotics are widespread among genera, most beneficial health effects of probiotics are strain-specific and cannot be extrapolated to other probiotics (Hill et al., 2014). Currently, there is still discussion regarding the efficacy of probiotics, as studies report contrasting results. Selection of the proper single or multi-strain probiotic strain is crucial for efficacy in various illnesses. In addition, administration of varying dosages with deviating interventional periods contribute to inconclusive results (Sanders et al., 2013).

Despite the concerns regarding the contrasting efficacy data, promising results have been reported in various disease areas in children and infants (Weichert et al., 2012). Probiotic supplementation to children seems to prevent respiratory tract infections. A Cochrane review of well-designed randomised controlled trials (RCT) demonstrated that the incidence of upper respiratory tract infections (URTI) was lower in the probiotic group compared to the placebo (Hao et al., 2011). Administration of Lactobacillus rhamnosus GG demonstrated a lower incidence of recurrent URTIs in children ageing $1-6$ years (odds ratio $=0.56$; $95 \%$ confidence interval: 0.31-0.99) (Hatakka et al., 2007). Additionally, there is accumulating evidence that probiotics are beneficial in the treatment of acute diarrhoea; in both duration as well as stool frequency (Allen et al., 2010). For instance, a metaanalysis evaluating the effect of Saccharomyces boulardii demonstrated a reduction of diarrhoea duration by one day (Szajewska and Skórka, 2009).

\section{Safety}

Although most probiotic strains are designated as GRAS (generally recognised as safe) by the United States Food and Drug Administration (FDA), there remain certain concerns regarding potential safety issues. For instance, probiotic bacteria can become opportunistic and translocate through the gastrointestinal barrier, might be toxic, have adverse immunologic effects or can potentially spread antibiotic resistance to pathogenic species (Klein, 2011).
Probiotic and synbiotic safety in children, particularly when immune compromised, remains unclear. These individuals have a defective microbial clearance and are thereby more susceptible to opportunistic bacteria (Boyle et al., 2006). An extensive exploratory safety analysis of probiotics by Hempel et al. (2011) indicated, however, that probiotics are safe. Additionally, a previous report by Van den Nieuwboer et al. (2014) concluded that there was no increased health risk in infants less than two years of age. As this study only focussed specific on participants under 24 months old, an overview of the safety data for infants and children older than 24 months is still lacking. Therefore, this reports aims to review the safety data of probiotic and synbiotic interventions focusing on the child population ageing 0 to 18 years old. In specific, it will provide an update with the most recent intervention studies on the previous safety analysis by Hempel et al. (2011). This analysis will provide a clear overview of any safety concerns for high-dosage and chronic probiotic use in at-risk child populations, by taking health conditions, probiotic intake and study duration into account.

\section{Methodology}

In order to analyse the safety of probiotics and synbiotics in children an extensive literature study was conducted. Clinical studies were retrieved from the online database PubMed (National Library of Medicine, includes MEDLINE). Eligible articles were retrieved using the search terms 'probiotics' or 'synbiotics' in combination with 'children,' 'kids' and 'adolescents.' This search strategy was complemented with filters to solely include human studies published within the last five years (2008-2013), thereby excluding all animal and in vitro studies. All studies were subsequently reviewed for clinical phase and status using clinical trials registry databases clinicaltrials.gov and isrctn. org. Articles were considered eligible if the investigators conducted an interventional study using a probiotic, a mixture of probiotics or synbiotics in children ageing between 0 and 18 years. All original and follow-up studies were included, without probiotic species or study design restrictions (both pilot studies as well as double blinded, randomised, placebo controlled studies were included). Both mechanistic studies as well as studies attempting to cure, treat, alleviate or prevent an illness were incorporated into this analysis. A total volume of 259 studies describing a probiotic or synbiotic intervention in participants aging from birth to 18 years were analysed according to their respective abstract and title for applicability and, subsequently, a full text analysis was conducted. Studies including a specific participant population concerning very young infants ageing between 0 and 24 months were excluded ( $n=73$; these data are described in Van den Nieuwboer et al., 2014). An additional 113 articles were excluded as no probiotic intervention was conducted during the study or did not meet the inclusion criteria. Finally, the safety data were analysed for 74 studies (Torii et al., 2011 
and Boonyaritichaikij et al., 2009 described two studies in one paper), of which all were original studies (Table 1).

The safety profile of the administered probiotics and synbiotics were assessed by means of the reported adverse events (AEs), and analysed according to their nature and quantity. AEs are defined as the occurrence of complications or illnesses, or worsening of the condition throughout the study. The adverse events were categorised according to the Common Terminology Criteria for Adverse Events (CTCAE version 4.0, NIH, 2009) classification system (Table 2). The CTCAE divides the AEs into 26 categories and grades according to the severity. This study did not grade the severity of the AEs as this data was missing or difficult to interpret. An extra category 'unspecified' was added, since not all reported AEs could be properly categorised. Furthermore, this review did not distinguish between relatedness and seriousness of the AEs, as this depends on judgement of the investigators, and overall meta-analyses.

Other relevant data, such as probiotic strains, dosage and intervention duration were taken into account for analysis of the intervention. Beneficial effects of probiotics are mainly strain specific, therefore it is essential to determine which strains have been tested at high-dosage and chronic use compared to their respective safety profile. This study was not designed to sufficiently evaluate the efficacy. It should be noted that this review uses the terms probiotics and synbiotics interchangeably, as the synbiotics contain probiotic strains.

\section{Results}

In the eligible 74 studies, a total of 15,885 participants were randomly allocated to the treatment and control arms. In the treatment arm, 8,472 participants were subjected to a probiotic and/or synbiotic treatment, with a drop-out rate of $7.96 \%$, resulting in a per-protocol population of 7.798 participants. In the control arm, 7,413 and 6,754 participants were allocated and analysed per-protocol respectively, corresponding with a drop-out rate of $8.89 \%$. Because some participants discontinued the study due to experienced AEs, all AEs in the allocated population were assessed to determine the safety profile. The majority of the studies were published between 2010 and 2011, whereas only two and six studies were published in 2013 and 2008 respectively. The median duration of the clinical studies was 37 days (range: 3-635), with an exposure equal or less than 3 months in $62(\sim 84 \%)$ interventions. Only five studies evaluated chronic exposure of probiotics by administration of equal or more than one year (Figure 1 illustrates the study durations in days). The identified subgroups of participants were: (1) healthy children; (2) children with an intestinal disorder; (3) children with an inflammatory disorder or allergy; (4) children with an infection; (5) immune compromised children; and (6) obese children.

The study population was considerably heterogeneous, as the participants' age ranged from 0 to 18 years. For instance, where some studies solely included infants between 0 and 48 months (El-Sawaf et al., 2013), other studies included

Table 1. Evaluated studies.

\begin{tabular}{|c|c|c|}
\hline Augustina et al., 2012 & Hojsak et al., 2010a,b & Sazawal et al., 2010 \\
\hline Aminabadi et al., 2011 & Hurduc et al., 2009 & Sentongo et al., 2008 \\
\hline Boonyaritichaikij et al., 2009 & Kerac et al., 2009 & Shafiei et al., 2011 \\
\hline Cazzola et al., 2010 & Kumar et al., 2013 & Simakachorn et al., 2011 \\
\hline Chen et al., 2010a,b & Leyer et al., 2009 & Singh et al., 2011 \\
\hline Cildir et al., 2009 & Lin et al., 2013, 2009 & Skovbjerg et al., 2009 \\
\hline Corrêa et al., 2011 & Lue et al., 2012 & Stecksén-Blicks et al., 2009 \\
\hline Dalgic et al., 2011 & Martínez Cañavate et al., 2009 & Sur et al., 2011 \\
\hline Dinleyici et al., 2009, 2011 & Matsuda et al., 2011 & Surono et al., 2011 \\
\hline El-Sawaf et al., 2013 & Merenstein et al., 2010, 2009 & Szachta et al., 2011 \\
\hline Eren et al., 2010 & Miele et al., 2009 & Szajewska et al., 2009 \\
\hline Fang et al., 2009 & Miniello et al., 2010 & Szymański et al., 2008 \\
\hline Francavilla et al., 2012, 2010 & Misra et al., 2009 & Tabbers et al., 2011 \\
\hline Gerasimov et al., 2010 & Narayanappa et al., 2008 & Tolone et al., 2012 \\
\hline Glavina et al., 2012 & Nixon et al., 2012 & Torii et al., 2011 \\
\hline Gøbel et al., 2012 & Oliva et al., 2012 & Vajro et al., 2011 \\
\hline Gotteland et al., 2008 & Ouwehand et al., 2009 & Vandenplas and De Hert, 2011 \\
\hline Guandalini et al., 2010 & Passariello et al., 2012 & Wada et al, 2010 \\
\hline Guerra et al., 2011 & Pérez et al., 2010 & Wanke and Szajewska, 2012 \\
\hline Han et al., 2012 & Rerksuppaphol and Rerksuppaphol, 2010, 2012 & Woo et al., 2010 \\
\hline Henker et al., 2008 & Riaz et al., 2012 & Wu et al., 2012 \\
\hline Heydarian et al., 2010 & Ruszczyński et al., 2008 & \\
\hline
\end{tabular}


Table 2. Common terminology clinical adverse events (version 4.0).

$\begin{array}{ll}\text { Category } & \text { Designation } \\ & \\ \text { Blood and lymphatic system disorders } & \text { I } \\ \text { Cardiac disorders } & \text { II } \\ \text { Congenital, familial and genetic disorders } & \text { III } \\ \text { Ear and labyrinth disorders } & \text { IV } \\ \text { Endocrine disorders } & \text { V } \\ \text { Eye disorders } & \text { VI } \\ \text { Gastrointestinal disorders } & \text { VII } \\ \text { General disorders and administration site conditions } & \text { VIII } \\ \text { Hepatobiliary disorders } & \mathrm{IX} \\ \text { Immune system disorders } & \mathrm{X} \\ \text { Infections and infestations } & \mathrm{XI} \\ \text { Injury, poisoning and procedural complications } & \mathrm{XII} \\ \text { Investigations } & \mathrm{XIII} \\ \text { Metabolism and nutrition disorders } & \mathrm{XIV} \\ \text { Musculoskeletal and connective tissue disorders } & \mathrm{XV} \\ \text { Neoplasms benign, malignant and unspecified (incl. } & \mathrm{XVI} \\ \text { cysts and polyps) } & \\ \text { Nervous system disorders } & \mathrm{XVII} \\ \text { Pregnancy, puerperium and perinatal conditions } & \mathrm{XVIII} \\ \text { Psychiatric disorders } & \mathrm{XIX} \\ \text { Renal and urinary disorders } & \mathrm{XX} \\ \text { Reproductive system and breast disorders } & \mathrm{XXI} \\ \text { Respiratory, thoracic and mediastinal disorders } & \mathrm{XXII} \\ \text { Skin and subcutaneous tissue disorders } & \mathrm{XXIII} \\ \text { Social circumstances } & \mathrm{XXIV} \\ \text { Surgical and medical procedures } & \mathrm{XXV} \\ \text { Vascular disorders } & \mathrm{XXVI} \\ \text { Unspecified } & \mathrm{XXVII} \\ & \\ & \end{array}$

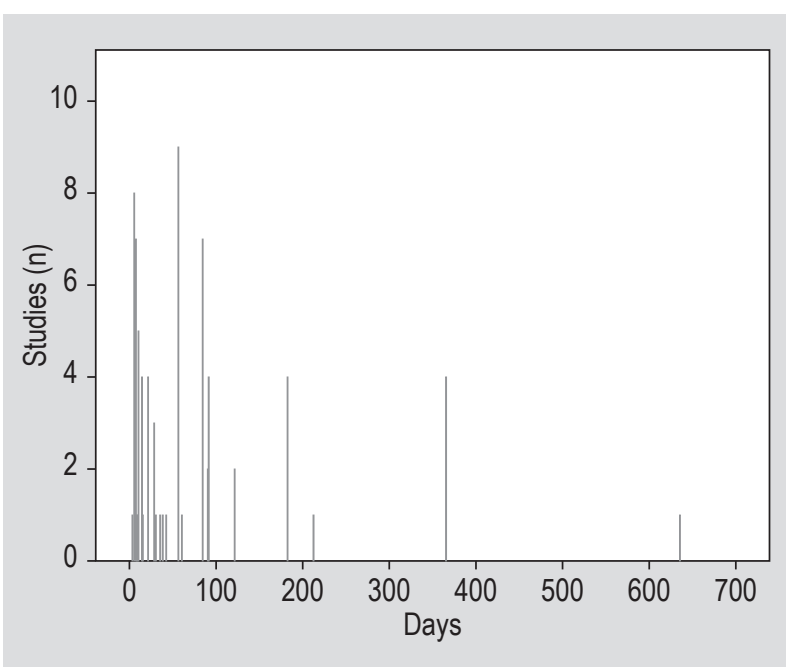

Figure 1. Study duration of each intervention in days.

children between one and 17 years (Miele et al., 2009). Figure 2 depicts the age range of eligible participants for each study.

\section{Intervention}

When focussing on the applied intervention in the treatment arm, $47.3 \%$ of the study products were noncommercial whereas $52.6 \%$ were commercially available. The study product was most often applied as a single probiotic formulation (59.7\%), followed by a probiotic mixture, consisting of two or more probiotic strains (28.5\%). Synbiotic formulations were less common, as $5.2 \%$ of the study products concerned a single synbiotic product, consisting of one probiotic species in combination with prebiotics and $6.5 \%$ of the formulations concerned a synbiotic mixture consisting of two or more probiotic species in combination with prebiotics. The specific strain designation was lacking in $42 \%$ of the supplemented probiotics. The probiotic genus, species and strain was lacking in one study (Shafiei et al., 2011) and one study administered the questionable unknown strain Saccharomyces thermophilus (Kumar et al., 2013), demonstrating the poor quality of intervention reporting.

In total 84 different probiotic strains were supplemented in the interventions, with the majority of participants receiving Lactobacillus casei Shirota $(\mathrm{n}=1,893)$. This large population can be attributed to a single study by Sur et al. (2011), evaluating whether L. casei Shirota has a beneficial role in protecting children (1-5 year) from acute diarrhoea in an urban slum community. The second most frequent administered probiotic strain was L. rhamnosus GG ( $\mathrm{n}=964)$. The bacterial species Streptococcus thermophilus, L. rhamnosus, Lactobacillus acidophilus, Bifidobacterium longum, Bifidobacterium bifidum, Bifidobacterium infantis, Lactobacillus plantarum (all lacking a specific strain designation) and the yeast $S$. boulardii were all administered to 400-900 participants each. Between 250 and 400 participants received each Pediococcus pentosaceus 16:1 LMG P-20608, Leuconostoc mesenteroides 2377:1 LMG P-20607, L. plantarum 2362 LMG P-20606, Lactobacillus paracasei F-19 LMG P-17806, L. casei DN-114 001, Bifidobacterium lactis HN019, Lactobacillus gasseri OLL2716 and the unspecified species Lactobacillus brevis, Lactobacillus salivarius, Lactobacillus helviticus, L. casei and Enterococcus faecum. L. acidophilus NCFM, L. rhamnosus T cell-1, Lactobacillus reuteri DSM17938, L. casei CRL431, Clostridium butyricum TO-A, Bacillus mesentericus TOA, Bifidobacterium breve (unspecified), L. rhamnosus LB21, Enterococcus faecalis T-110, Lactobacillus johnsonii La1, L. salivarius PM-A0006, L. rhamnosus PEN (2593), L. rhamnosus Oxy (2595), L. rhamnosus $\mathrm{E} / \mathrm{N}$ (2594), B. lactis Bi-07, L. paracasei (unspecified) and B. lactis DN-173010 were all supplemented to 100-250 participants. The remaining 45 probiotic strains were supplemented to less than 100 participants, making the respective safety data less reliable. The allocated participants for each strain are illustrated in Figure 3. 


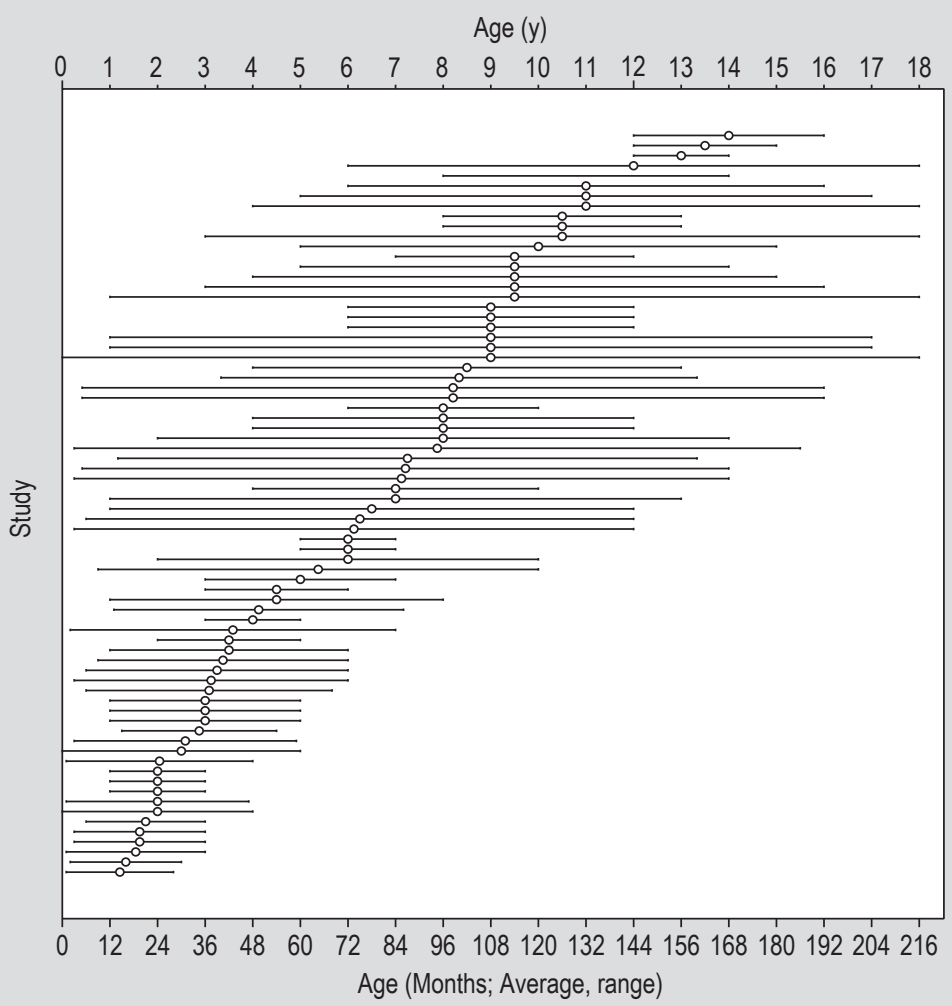

Figure 2. Age range in months and years for each study. The figure illustrates the youngest, average and oldest participant age included in each study.

Analysis of the applied dosage in cfu for each strain is shown in Figure 3. The median supplemented dosage was $2.4 \times 10^{9} \mathrm{cfu}$ per day, ranging from the lowest dosage of $B$. mesentericus TO-A $\left(3.0 \times 10^{6} \mathrm{cfu} /\right.$ day $)$ to the highest dosage of $1.5 \times 10^{11} \mathrm{cfu} /$ day with $L$. acidophilus L-92. The daily administered dosage was lacking or insufficiently reported in $29 \%$ of all the applied probiotic species. Several probiotic strains were tested according to a large range of dosages, for instance, S. boulardii, L. reuteri ATCC 55730, L. rhamnosus GG, B. bifidum (unspecified), B. longum (unspecified) and L. acidophilus (unspecified). The other strains were tested at a low dosage, a narrow range, the administered daily cfu was not reported or were only evaluated at a single dosage. There was no information available on the supplemented dosage for the strains Lactococcus casei, Lactococcus cremoris CNCM I-1631, Lactococcus lactis (unspecified), Lactococcus diacetylactis, Lactococcus plantarum (unspecified), Lactococcus rhamnosus (unspecified), Leuconostoc cremoris (unspecified), Saccharomyces florentinus (unspecified), L. paracasei (unspecified), L. helveticus R0052 (I-1722), Lactobacillus coryniformis CECT5711, L. gasseri CECT5714, L. casei DN-114 001/ CNCM I-1518, L. acidophilus DDS-1, B. lactis UABLA-12, B. infantis R0033 (I-3424), B. bifidum R0071 (I-3425) and B. breve (unspecified).

Different afflictions require different probiotic properties for alleviation, mitigation, prevention or treatment. Figure
4 demonstrates the applied cfu for each subgroup and Figure 5 illustrates the allocated and analysed participants for each subgroup for the treatment and control arm. When focussing on the specific subgroups, the median intervention duration for the healthy participants was 90 days (range: 10-365). A total of 4,780 and 3,900 healthy participants were allocated to the treatment and control arm respectively in $19(25.6 \%)$ studies. Children received on average $6.5 \times 10^{9} \mathrm{cfu}$ per day (range: $1.9 \times 10^{7}-4.0 \times 10^{10}$ ), with $L$. casei Shirota distributed most frequently among the participants $(\mathrm{n}=1,893)$.

The subgroup of gastrointestinal disorders consisted of children with acute diarrhoea ( $\leq 7$ days), gastroenteritis, rota viral diarrhoea, constipation (functional and chronic), ulcerative colitis, Hirschprung disease, irritable bowel syndrome, recurrent abdominal pain and short bowel syndrome. A total of 1,493 and 1,467 participants were allocated to the treatment and control arm respectively in 24 (32.4\%) studies. These children participated in interventions with a median duration of 10 days (range: 5-365) and received on average $3.12 \times 10^{9}$ (range: $3.0 \times 10^{6}-1.0 \times 10^{10}$ ) $\mathrm{cfu} /$ day. The majority in this subgroup received the yeast $S$. boulardii $(\mathrm{n}=435)$.

The subgroup inflammatory disorders and allergies were combined as these included the disorders atopic dermatitis, asthma, allergic rhinitis and pollen fever. In 13 (17.5\%) 


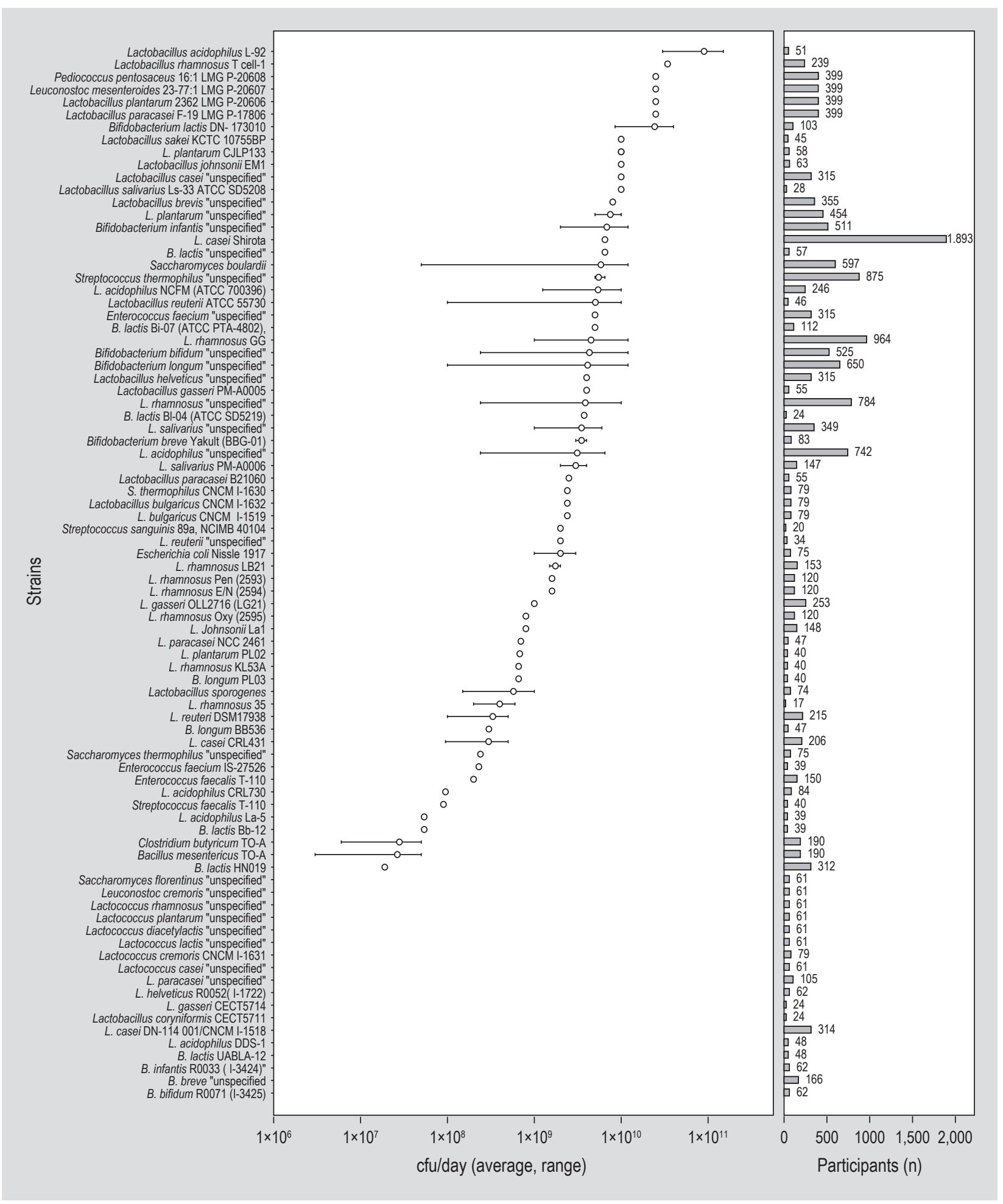

Figure 3. Range of daily administered cfu for each probiotic strain, and the respective participants receiving the strain.

studies 561 and 548 participants were allocated to the treatment and control arm respectively. The median interventional period was 72 days (range: 56-121), in which the majority received L. salivarius PM-A0006 ( $\mathrm{n}=147)$. The children received on average $2.05 \times 10^{10} \mathrm{cfu}$ per day, ranging from the lowest applied dosage of $1.0 \times 10^{8} \mathrm{cfu}$ to the highest dosage of $1.5 \times 10^{11} \mathrm{cfu}$ per day.

The subgroup of children with an infection consisted of 10 (13.5\%) studies and includes participants with a Helicobacter pylori infection, children colonised by vancomycin- 


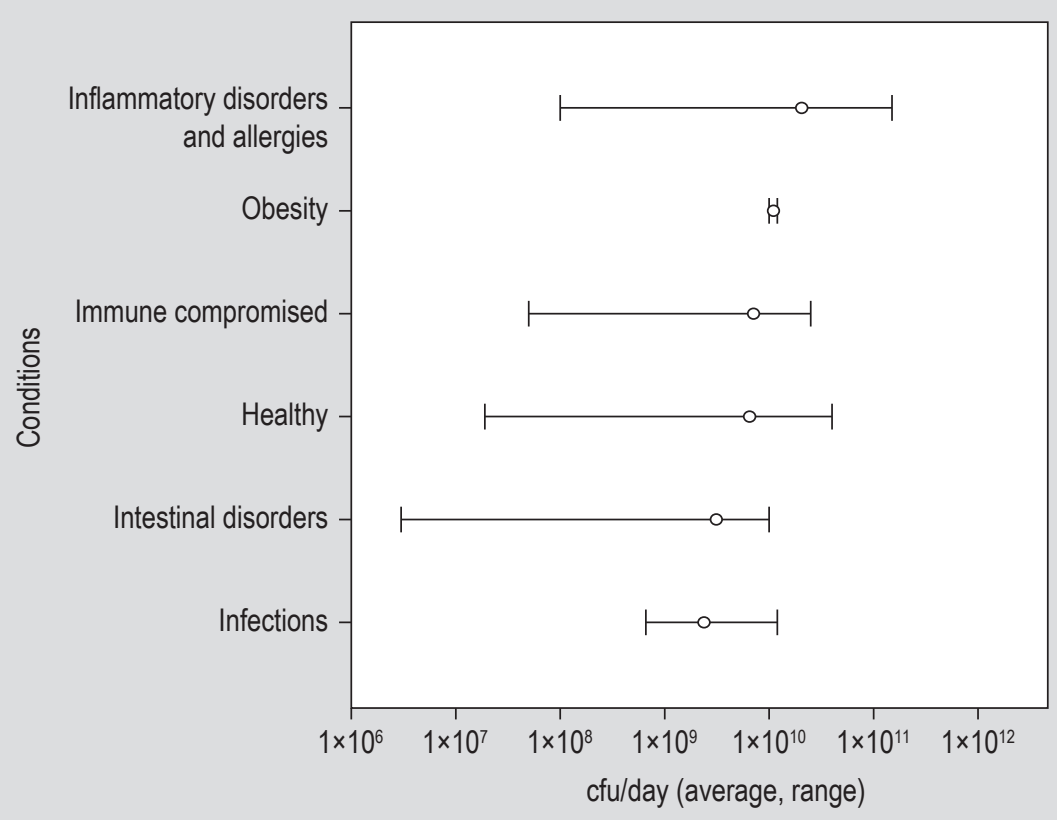

Figure 4. Minimal, average and maximal applied dosage in cfu per day for each health condition.

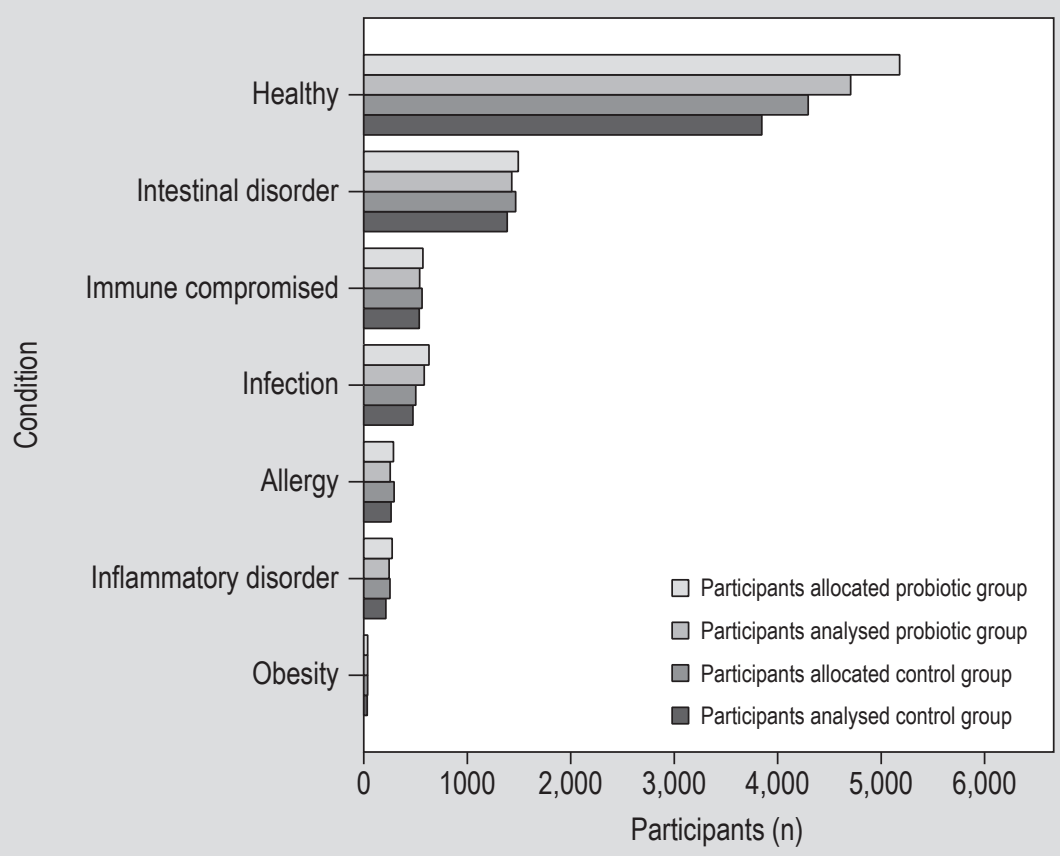

Figure 5. Frequency of allocated and analysed participants in the treatment and control arm for each health condition.

resistant enterococci, participants infected by the amoeba Entamoeba histolytica, children with otitis media and children requiring antibiotic treatment. A total of 630 and 502 participants were allocated to the treatment and control arm respectively. The median duration of the intervention was 12.5 days (range: 7-365), in which the participants received on average $2.38 \times 10^{9} \mathrm{cfu}$ per day (range: $6.6 \times 10^{8}$ $1.2 \times 10^{10} \mathrm{cfu}$ ). L. johnsonii La1 was administered most frequently in this subgroup $(\mathrm{n}=148)$.
The immune compromised subgroup included hospitalised and critical ill children, children requiring mechanical ventilation and enteral nutrition, suffering from severe malnutrition or children affected by malignancies. In 6 (8.1\%) studies, a total of 970 and 959 participants were allocated to the treatment and control arm. The participants received an intervention for a median of 10.8 days (range: $7-56$ ), with a mean daily cfu of $7.09 \times 10^{9}$ (range: $5.0 \times 10^{7}-2.5 \times 10^{10}$ cfu/day). P. pentosaceus 16:1 LMG P-20608, L. mesenteroides 
23-77:1 LMG P-20607, L. paracasei F-19 LMG P-17806 and L. plantarum 2362 LMG P-20606 were administered to the majority in this subgroup $(n=399)$.

Finally, the obese subgroup consisted of two studies (2.7\%) with a median duration of 70 days (range: $56-84$ ). Participants received on average $1.1 \times 10^{10} \mathrm{cfu}$ per day (range: $1.0 \times 10^{10}-1.2 \times 10^{10} \mathrm{cfu} /$ day). A total of 38 and 37 participants were allocated to the treatment and control arm respectively, whereas the majority received L. salivarius Ls-33 ATCC SD5208 ( $n=28)$. Considering the above mentioned data, majority of the participants were healthy, and probiotics were tested for each condition according to a large range of dosages (except for obesity).

\section{Safety}

The 74 studies were analysed for their non-specific overall safety statement of the study product, regardless of the reported adverse events. As illustrated in Figure 6, the safety statement that 'no AEs were reported during the intervention' was most common $(n=25)$ and the study product was 'well tolerated' in 13 studies. In seven interventional studies there was 'no significant difference in AEs between study groups', and six papers stated there was 'no AE related to the study product.' One study (Hurduc et al., 2009) indicated that the intervention led to 'reduced side effects', whereas Agustina et al. (2012) stated there were 'increased complications' Strikingly, safety and AEs were not discussed in 21 (28.4\%) studies; these studies did not address any AEs and risks of probiotic or synbiotic interventions.

By analysing the clinical data according to the CTCAE, a total of 3,418 and 3,879 AEs were identified in the treatment and the control arm respectively. Gastrointestinal disorders (category VII) occurred most frequently $(n=5,470)$ followed by infections and infestations (category XI; $\mathrm{n}=884$ ) and respiratory, thoracic and mediastinal disorders (category XXII; n=546). Figure 7A illustrates the distribution of all reported AEs across both intervention arms. The most common AEs were diarrhoea (VII), dysentery episodes (VII), URTIs (XI), rhinorrhoea (XXII) and cough (XXII). A total of 122 AEs were not properly specified and thus could not be categorised according to the CTCAE. This concerned 44 AEs in the treatment arm and 78 AEs in the control arm. Except for general disorders and administration site conditions (category VIII; $\mathrm{n}=220$ ), AEs in the other CTCAE categories did not occur, or in a relative low frequency.

Subgroup analysis indicated that a gastrointestinal disorder (VII) was the most common AE reported by healthy participants; 2,480 and 2,665 AEs in the treatment and control arm respectively (Figure $7 \mathrm{~B}$ ). AEs in the category respiratory, thoracic and mediastinal disorders (XXII) and infections and infestations(XI) occurred relatively frequent ( $n=544$ and 540 respectively). Despite of two single events in the treatment group, an immune system disorder $(\mathrm{X})$ and a surgical or medical procedure (XXV), the frequency of reported AEs in the treatment group was lower for each CTCAE category. Overall the incidence of AEs was lower in the group receiving probiotics or synbiotics compared to the control group, regardless of the 880 more participants that were allocated to this intervention group. Remarkable is the low frequency of reported AEs in the gastrointestinal disorder subgroup, with a total $\mathrm{AE}$ count of 50 . In this relatively large group of participants $(n=2,960)$, gastrointestinal disorders (VII) were most commonly observed $(n=29)$, followed by

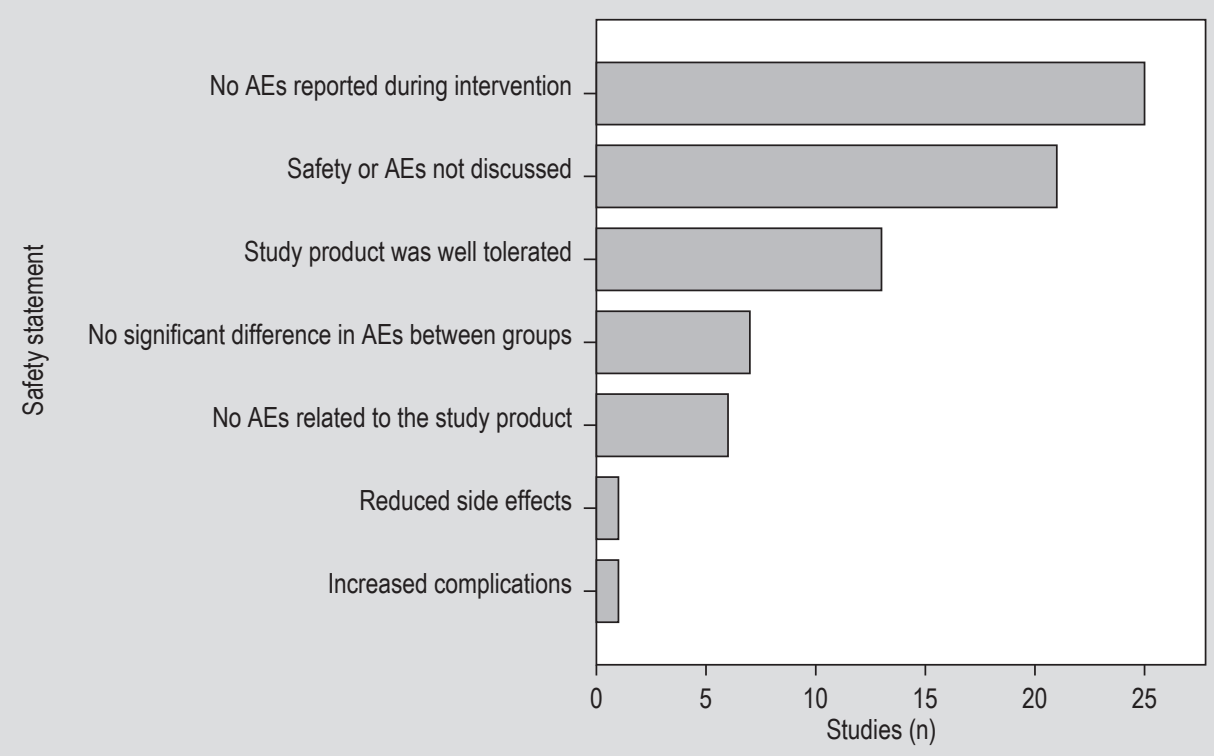

Figure 6. Overall non-specific safety statement of each study. 

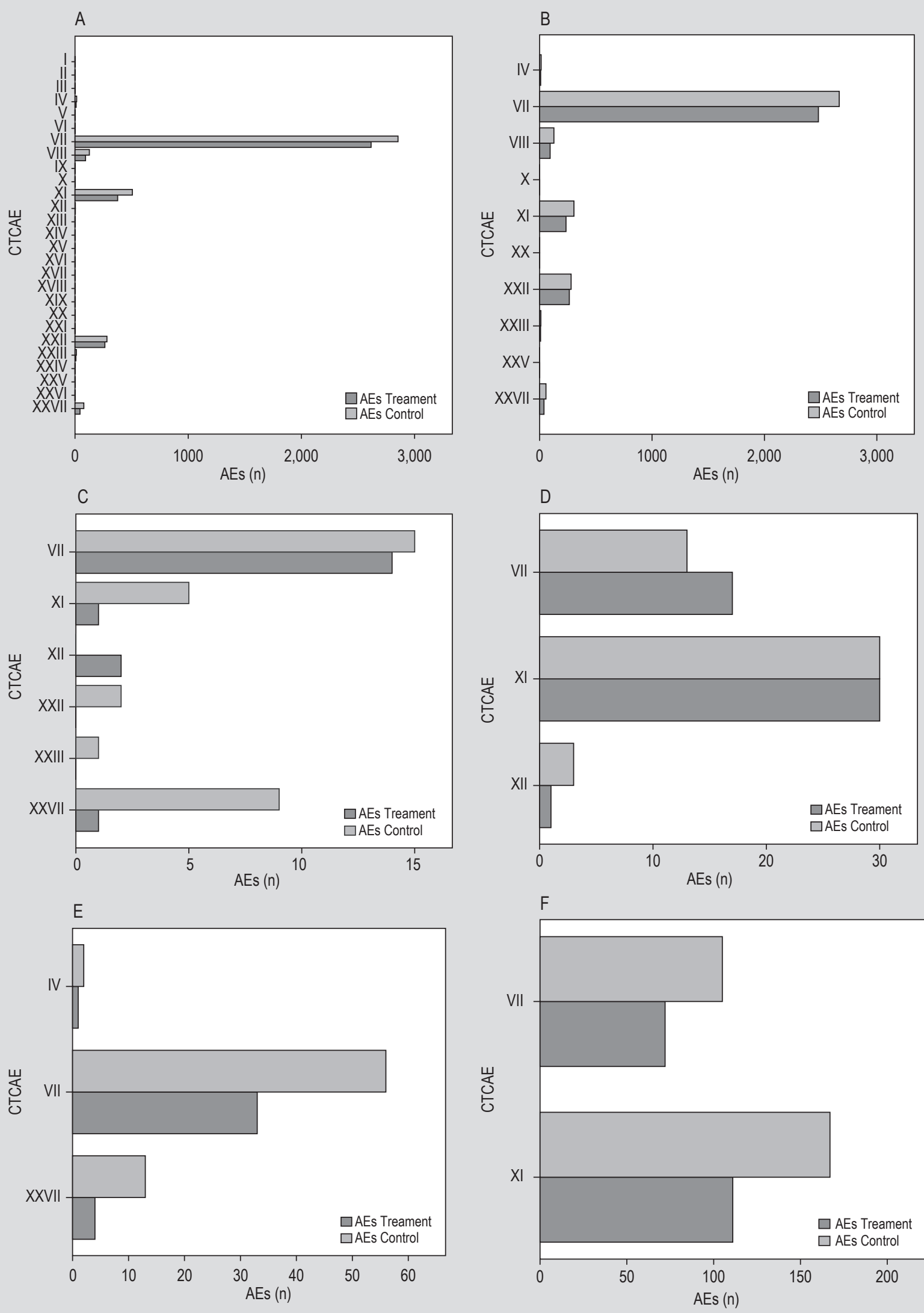

Figure 7. Reported adverse events (AE) in the treatment and control arm. (A) Total AE in children; (B) AEs in healthy children; (C) AEs in children with an intestinal disorder; (D) AEs in children with an allergy or inflammatory disorder; (E) AEs in infected children; (F) AEs in immune compromised children. 
'unspecified' AEs (XXVII; $\mathrm{n}=10$ ). The occurrence of AEs was higher in the control group in all CTCAE categories, except for two unrelated 'injury, poisoning and procedural complications' (XII) in the treatment group (Figure 7C). In the subgroup inflammatory disorders and allergies, infections and infestations (XI) occurred most frequently followed by gastrointestinal disorders (VII). Four more gastrointestinal AEs were reported in the treatment group, three diarrheal events and one abdominal colic event. Although of concern, the frequency of AEs in this group was relatively low (Figure 7D). Gastrointestinal disorders (VII) occurred most frequently in the subgroup of infected children, whereas the incidence was lower in the treatment group ( $\mathrm{n}=33$ vs 56 respectively). This was mainly due to a higher incidence of diarrhoeal episodes in the control group. The total frequency of AEs was 109, with 38 and 71 AEs in the treatment and control arm respectively, whereas the number of AEs in the treatment group was lower for each CTCAE category (Figure 7E). In the immune compromised subgroup infections and infestations (XI) and gastrointestinal disorders (VII) were most often observed. This concerned episodes of sepsis and diarrhoea and vomiting ( $\mathrm{n}=137,125$ and 72 respectively). No AEs of the other categories were reported and in both CTCAE categories (XI and VII) the frequency of AEs was lower in the treatment arm compared to the control arm (Figure 7F). There were no AEs reported in the obesity group.

\section{Conclusion and discussion}

Analysis of the 74 interventional studies indicated that in the setting of a controlled clinical trial, probiotic and synbiotic administration in children between the age of 0 and 18 years is not associated with an increased health risk. This statement is however limited to the supplemented strains and their respective dosage, exposure duration and target patient population. As probiotic properties are mainly strain-specific, both efficacy as well as safety data cannot be extrapolated to other probiotics of the same species, or probiotic organisms in general (Hill et al., 2014). This update is in line with previous analyses, indicating that probiotics are safe, even in infants and immune compromised adults (Hempel et al., 2011; Van den Nieuwboer et al., 2014, 2015).

Data indicate no significant difference between documented AEs in the treatment and control group $(n=3,418$ and 3,879 respectively); for the total population as well as the specific patient populations. For each patient population, the incidence of AEs in each category was lower in the treatment group compared to the control group (except for two more AEs in the category gastrointestinal disorders (VII) in children inflammatory disorders and allergy; ns). The overall incidence rate of AEs was 0.40 and 0.52 in the treatment and control arm respectively. The majority of the AEs in the 'healthy' subgroup, children receiving probiotics for disease prevention, were non- serious of nature (diarrhoea, cough and URTIs) and often the frequency was lower in the probiotic group. Leyer et al. (2009) demonstrated a significant lower incidence of fever (VIII) and cough (XXII) after administration of L. acidophilus NCFM and a reduction in rhinorrhoea (XXII) with a combination of L. acidophilus NCFM and B. lactis $\mathrm{Bi}-07$. The reduction and cough and fever could also be observed after administration of a commercial product containing L. acidophilus and B. bifidum (Rerksuppaphol and Rerksuppaphol, 2010). Sur et al. (2011) demonstrated a significant reduction in diarrhoea (VII) after L. casei Shirota administration $(P=0.01)$, whereas administration of L. rhamnosus GG induced significantly less URTIs (Hojsak et al., 2010a,b). Significant lower dysentery, pneumonia episodes and lower respiratory tract infections were observed in the treatment group that received B. lactis HN019 (Sazawal et al., 2010). Only one intervention in the healthy population evaluating the effects of calcium and probiotics on the incidence and duration of acute diarrhoea and acute respiratory tract infections indicated increased complications after daily supplementation of $0.5 \times 10^{9} \mathrm{cfu}$ L. reuteri DSM17938 (Agustina et al., 2012). In this study, healthy 1-6 year old children from low socioeconomic communities reported a significant change in bowel habits (less regular defecation) compared to the ' $L$. casei' and the 'calcium' groups. In addition, three children developed asthma in the reuteri group. Although significant, this data was based on very few cases. Furthermore, the study by Francavilla et al. (2012) did not observe any of these AEs during administration of L. reuteri DSM17938. Both Tolone et al. (2012) and Hurduc et al. (2009) documented significant less AEs in treatment group compared to the control group in $H$. pylori infected children. Perhaps of more interest, is that there was no significantly higher occurrence rate of AEs in the treatment group in immune compromised children. On the contrary, significantly less AEs were observed compared to the control arm (Hojsak et al., 2010a,b; Kumar et al., 2013; Wada et al., 2010). These promising results indicate that the current administered probiotics can be safely evaluated in immune compromised children, and thereby pave the way for further exploration of the therapeutic potential of probiotics and synbiotics, or at least decrease complications and comorbidity.

Overall, none of the serious AEs were considered related to the probiotic product. None of the reported events of infection, bacteraemia or sepsis were associated with the administered probiotics, and no probiotic species were positively cultured from an infection during the intervention and follow-up periods. As probiotics are living organisms, they have the potential to induce systemic infections, adjuvant side-effects, cause immunomodulation, are able to transfer genes and can possess harmful metabolic activities (Salminen et al., 1998). Systemic infections due to lactic acid bacteria (LAB) occur rarely compared to other opportunistic bacteria (Dicks and Botes, 2010). Nevertheless, over 200 
case reports demonstrated that Lactobacillus species are able to cause, and are often associated with bacteraemia and endocarditis (Cannon et al., 2005). Although of concern, only a very small portion (1.7\%) was likely related to heavy dairy consumption, and no cases were associated with probiotic intake. In agreement, despite a rapid increase in L. rhamnosus GG intake in Finland, there has been no increase in Lactobacillus bacteraemia frequency observed since 1990 (Salminen et al., 2002). In addition, LAB have been safely used for many decades, since humans started consuming fermented milk products.

Previous case reports reported three Lactobacillus sepsis cases after probiotic administration of L. rhamnosus GG in infants with short-bowel syndrome (SBS; De Groote et al., 2005; Kunz et al., 2004). In addition, Munakata et al. (2010) and Ku et al. (2006) observed D-lactic acidosis in children with SBS after supplementation with probiotic species. SBS is characterised as a reduction in functional gut mass, thereby being insufficient to maintain nutrient and fluids levels (Reddy et al., 2013). SBS is associated with increased intestinal permeability and bowel inflammation (Cole et al., 2010; Reddy et al., 2013) and thus renders the individual more susceptible for bacterial translocation and sepsis. Nevertheless, the small RCT by Sentongo et al. (2008) did not indicate any AEs, and several previous case reports and case control studies in children with SBS encountered no health risks (Reddy et al., 2013). It is beyond the scope of this study to carefully investigate the isolated case reports on-by-one to fully understand the reason for such AEs. However, within the controlled framework of RCTs these side effects have not been reported. One should however bear in mind that this cross-over RCT only allocated nine participants (Sentongo et al., 2008). Regarding the other immune compromised children within this subgroup, the level of inflammation determines the risk of infection and outcome of the patient (Bengmark, 1998). Due to on-going systemic inflammation, these children are more susceptible to complications, bacterial translocation and sepsis (Alverdy et al., 2003). Increased surveillance thus remains essential when evaluating probiotics in this susceptible population.

Despite a substantial number of participants with an intestinal disorder were included in the analysis $(n=2,960)$, only 50 AEs were documented. Similar results were observed in participants with an inflammatory disorder or allergy; 1,109 participants reported a total of 94 AEs. The participants in these subgroups received a wide range of dosages, whereas some participants received a very high dosage of $1.5 \times 10^{11} \mathrm{cfu}$ of $L$. acidophilus L-92 per day with no significant difference in AEs (Torii et al., 2011). These data further underpin the safety of this strain in children. In all patient subgroups probiotic strains were evaluated exceeding $1.0 \times 10^{10} \mathrm{cfu} /$ day. Although promising, preferably all strains should be tested at very high dosages in each patient population to establish an optimal dosage- response relation in children. In addition, a higher exposure of probiotic organisms could be associated with a higher risk or incidence of AEs. The exposure duration was overall less than three months and there was a lack of available long-term follow-up studies; the safety profile of chronic probiotic exposure in children thus remains undetermined. Although currently long-term probiotic administration (Hatakka et al., 2001; Saavedra et al., 2004) and long-term effects after administration (up to 10 years) do not seem to be associated with adverse health risks (Kalliomäki et al., 2003; Luoto et al., 2010), these data are limited. More focus on long-term effect evaluation is essential in future study designs.

Analysis of the 74 papers identified a serious lack of proper documentation of the intervention as well as safety. Data is less valuable since $42 \%$ of the applied probiotics lacked a specific strain designation, and even a case were no genus or species was provided. Since properties of specific strains cannot be generalised, it is not possible to associate the efficacy and safety data to all probiotics. In addition, incomplete documentation of applied dosage impairs a proper analysis. Future research with data from these studies should thus be cross-checked and possibly reclassified. In addition, taxonomy of the probiotic organisms occasionally seems peculiar (e.g. Saccharomyces thermophilus). Proper strain identification by PCR can provide a definite answer which organism is applied to the participants. Regarding the safety, $28 \%$ of the studies solely focussed on efficacy rather than taking safety into account; these studies did not discuss AEs or the safety aspects of the intervention in any kind. The poor documentation is likely to be attributable to the large portion of commercial available products that were supplemented (52.6\%). Investigators probably rely on previous reported safety data and specific product formulation (e.g. strain and cfu) is in these cases often undisclosed.

The majority of the studies did not provide any AEs or only described uncommon reported AEs and thereby did not quantify or discuss the common AEs such as diarrhoea, flatulence or nausea. This likely led to an underrepresentation of several CTCAE categories and could affect overall conclusions. Incidences of serious AEs are often poor described and AEs are designated as unrelated to the study product, whilst large meta-analyses can provide new insights in the correlation between AEs and probiotic products.

The efficacy is essential for a proper risk-benefit analysis, and the ratio between AEs and documented beneficial effects is thus essential safety evaluation. If the potential beneficial therapeutic effects of a probiotic or synbiotic product outweigh the associated adverse health effects, it may justify the use of the product. This study, however, did not focus on the efficacy but solely on safety, although a reduction in 
the incidence and duration of diarrhoea was often observed. This study did not stratify for the formulation or commercial availability of the probiotic products. Whether a single probiotic, a probiotic mixture or synbiotic product is more efficacious remains to be determined.

A clear general safety conclusion is nearly impossible due to the inconsistent and imprecise $\mathrm{AE}$ documentation in combination with the vast variety in supplemented strains, dosages, administration regimes, target populations and outcomes. Very few studies address specifically probiotic complications and are not designed to assess the safety profile. Additionally, safety should be evaluated on a strainby-strain basis, depending on long-term and high dosage exposure. Based on the study by Hempel et al. (2011) combined with the current data, we still cannot provide a decisive safety profile of probiotics and synbiotics in children, however, based on data from controlled clinical trials, probiotics and synbiotics seem to be safe in children between 0 and 18 years. In addition, with respect to the previous safety studies in immune compromised adults and very young infants (Van den Nieuwboer et al., 2014, 2015) we argue that probiotic and synbiotic administration in a controlled setting of a RCT is safe, even in the vulnerable population. Therefore we urge investigators to further explore the potential of probiotics while at the same time designing properly powered and controlled clinical trials with standardised AE reporting.

\section{Acknowledgements}

We would like to thank Joop Orsouw for optimisation of the figures. The authors declare no conflict of interest.

\section{References}

Agustina, R., Kok, F.J., Van de Rest, O., Fahmida, U., Firmansyah, A., Lukito, W., Feskens, E.J., Van den Heuvel, E.G., Albers, R. and Bovee-Oudenhoven, I.M., 2012. Randomized trial of probiotics and calcium on diarrhea and respiratory tract infections in Indonesian children. Pediatrics 129: e1155-e1164.

Allen, S.J., Martinez, E.G., Gregorio, G.V. and Dans, L.F., 2010. Probiotics for treating acute infectious diarrhoea. Cochrane Database of Systematic Reviews 11.

Alonso, V.R. and Guarner, F., 2013. Linking the gut microbiota to human health. British Journal of Nutrition 109: S21-S26.

Alverdy, J.C., Laughlin, R.S. and Wu, L., 2003. Influence of the critically ill state on host-pathogen interactions within the intestine: gutderived sepsis redefined. Critical Care Medicine 31: 598-607.

Aminabadi, N.A., Erfanparast, L., Ebrahimi, A. and Oskouei, S.G., 2011. Effect of chlorhexidine pretreatment on the stability of salivary lactobacilli probiotic in six-to twelve-year-old children: a randomized controlled trial. Caries Research 45: 148-154.

Bengmark, S., 1998. Ecological control of the gastrointestinal tract. The role of probiotic flora. Gut 42: 2-7.
Boonyaritichaikij, S., Kuwabara, K., Nagano, J., Kobayashi, K. and Koga, Y., 2009. Long-term administration of probiotics to asymptomatic pre-school children for either the eradication or the prevention of Helicobacter pylori infection. Helicobacter 14: 202-207.

Boyle, R.J., Robins-Browne, R.M. and Tang, M.L., 2006. Probiotic use in clinical practice: what are the risks?. American Journal of Clinical Nutrition 83: 1256-1264.

Buccigrossi, V., Nicastro, E. and Guarino, A., 2013. Functions of intestinal microflora in children. Current Opinion in Gastroenterology 29: 31-38.

Cannon, J.P., Lee, T.A., Bolanos, J.T. and Danziger, L.H., 2005. Pathogenic relevance of Lactobacillus: a retrospective review of over 200 cases. European Journal of Clinical Microbiology and Infectious Diseases 24: 31-40.

Cazzola, M., Pham-Thi, N., Kerihuel, J.C., Durand, H. and Bohbot, S., 2010. Efficacy of a synbiotic supplementation in the prevention of common winter diseases in children: a randomized, double-blind, placebo-controlled pilot study. Therapeutic Advances in Respiratory Disease 4: 271-278.

Chen, C.C., Kong, M.S., Lai, M.W., Chao, H.C., Chang, K.W., Chen, S.Y., Huang, Y.C., Chiu, C.H., Li, W.C., Chen, C.J. and Lin, T.Y., 2010aa. Probiotics have clinical, microbiologic, and immunologic efficacy in acute infectious diarrhea. The Pediatric Infectious Disease Journal 29: 135-138.

Chen, Y.S., Lin, Y.L., Jan, R.L., Chen, H.H. and Wang, J.Y., $2010 \mathrm{~b}$. Randomized placebo-controlled trial of lactobacillus on asthmatic children with allergic rhinitis. Pediatric Pulmonology 45: 1111-1120.

Cildir, S.K., Germec, D., Sandalli, N., Ozdemir, F.I., Arun, T., Twetman, S. and Caglar, E., 2009. Reduction of salivary mutans streptococci in orthodontic patients during daily consumption of yoghurt containing probiotic bacteria. European Journal of Orthodontics 31: 4.07-411.

Cole, C.R., Frem, J.C., Schmotzer, B., Gewirtz, A.T., Meddings, J.B., Gold, B.D. and Ziegler, T.R., 2010. The rate of bloodstream infection is high in infants with short bowel syndrome: relationship with small bowel bacterial overgrowth, enteral feeding, and inflammatory and immune responses. Journal of Pediatrics 156: 941-947.

Corrêa, N.B., Penna, F.J., Lima, F.M., Nicoli, J.R. and Luciano Filho, A.P., 2011. Treatment of acute diarrhea with Saccharomyces boulardii in infants. Journal of Pediatric Gastroenterology and Nutrition 53: 497-501.

Dalgic, N., Sancar, M., Bayraktar, B., Pullu, M. and Hasim, O., 2011. Probiotic, zinc and lactose-free formula in children with rotavirus diarrhea: are they effective? Pediatrics International 53: 677-682.

D’Antiga, L., Dhawan, A., Davenport, M., Mieli-Vergani, G. and Bjarnason, I., 1999. Intestinal absorption and permeability in paediatric short-bowel syndrome: a pilot study. Journal of Pediatric Gastroenterology and Nutrition 29: 588-593.

De Groote, M.A., Frank, D.N., Dowell, E., Glode, M.P. and Pace, N.R., 2005. Lactobacillus rhamnosus GG bacteremia associated with probiotic use in a child with short gut syndrome. Pediatric Infectious Disease Journal 24: 278.

Dicks, L.M. and Botes, M., 2010. Probiotic lactic acid bacteria in the gastro-intestinal tract: health benefits, safety and mode of action. Beneficial Microbes 1: 11-29. 
Dinleyici, E.C., Eren, M., Dogan, N., Reyhanioglu, S., Yargic, Z.A. and Vandenplas, Y., 2011. Clinical efficacy of Saccharomyces boulardii or metronidazole in symptomatic children with Blastocystis hominis infection. Parasitology Research 108: 541-545.

Dinleyici, E.C., Eren, M., Yargic, Z.A., Dogan, N. and Vandenplas, Y., 2009. Clinical efficacy of Saccharomyces boulardii and metronidazole compared to metronidazole alone in children with acute bloody diarrhea caused by amebiasis: a prospective, randomized, open label study. American Journal of Tropical Medicine and Hygiene 80: 953-955.

Ege, M.J., Mayer, M., Normand, A.C., Genuneit, J., Cookson, W.O., Braun-Fahrländer, C., Heederik, D., Piarroux, R. and Von Mutius, E., 2011. Exposure to environmental microorganisms and childhood asthma. New England Journal of Medicine 364: 701-709.

El-Sawaf, M., Siddiqui, S., Mahmoud, M., Drongowski, R. and Teitelbaum, D.H., 2013. Probiotic prophylaxis after pullthrough for Hirschsprung disease to reduce incidence of enterocolitis: a prospective, randomized, double-blind, placebo-controlled, multicenter trial. Journal of Pediatric Surgery 48: 111-117.

Eren, M., Dinleyici, E.C. and Vandenplas, Y., 2010. Clinical efficacy comparison of Saccharomyces boulardii and yogurt fluid in acute non-bloody diarrhea in children: a randomized, controlled, open label study. American Journal of Tropical Medicine and Hygiene 82: 488-491.

Fang, S.B., Lee, H.C., Hu, J.J., Hou, S.Y., Liu, H.L. and Fang, H.W., 2009. Dose-dependent effect of Lactobacillus rhamnosus on quantitative reduction of faecal rotavirus shedding in children. Journal of Tropical Pediatrics 55: 297-301.

Francavilla, R., Lionetti, E., Castellaneta, S., Ciruzzi, F., Indrio, F., Masciale, A., Fontana, C., La Rosa, M.M., Cavallo, L. and Francavilla, A., 2012. Randomised clinical trial: Lactobacillus reuteri DSM 17938 vs. placebo in children with acute diarrhoea - a double-blind study. Alimentary Pharmacology and Therapeutics 36: 363-369.

Francavilla, R., Miniello, V., Magistà, A.M., De Canio, A., Bucci, N., Gagliardi, F., Lionetti, E., Castellaneta, S., Polimeno, L., Peccasiri, L., Indrio, F. and Cavallo, L., 2010. A randomized controlled trial of Lactobacillus GG in children with functional abdominal pain. Pediatrics 126: e1445-e1452.

Gerasimov, S.V., Vasjuta, V.V., Myhovych, O.O. and Bondarchuk, L.I., 2010. Probiotic supplement reduces atopic dermatitis in preschool children. American Journal of Clinical Dermatology 11: 351-361.

Glavina, D., Goršeta, K., Škrinjarić, I., Negovetić Vranić, D., Mehulić, K. and Kožul, K., 2012. Effect of LGG yoghurt on Streptococcus mutans and Lactobacillus spp. salivary counts in children. Collegium Antropologicum 36: 129-132.

Gøbel, R.J., Larsen, N., Jakobsen, M., Mølgaard, C. and Michaelsen, K.F., 2012. Probiotics to adolescents with obesity: effects on inflammation and metabolic syndrome. Journal of Pediatric Gastroenterology and Nutrition 55: 673-678.

Gotteland, M., Andrews, M., Toledo, M., Muñoz, L., Caceres, P., Anziani, A., Wittig, E., Speisky, H. and Salazar, G., 2008. Modulation of Helicobacter pylori colonization with cranberry juice and Lactobacillus johnsonii La1 in children. Nutrition 24: 421-426.
Guandalini, S., Magazzu, G., Chiaro, A., La Balestra, V., Di Nardo, G., Gopalan, S., Sibal, A., Romano, C., Canani, R.B., Lionetti, P. and Setty, M., 2010. VSL\# 3 improves symptoms in children with irritable bowel syndrome: a multicenter, randomized, placebo-controlled, double-blind, crossover study. Journal of Pediatric Gastroenterology and Nutrition 51: 24-30.

Guarner, F., Bourdet-Sicard, R., Brandtzaeg, P., Gill, H.S., McGuirk, P., Van Eden, W., Versalovic, J., Weinstock, J.V. and Rook, G.A., 2006. Mechanisms of disease: the hygiene hypothesis revisited. Nature Clinical Practice Gastroenterology and Hepatology 3: 275-284.

Guerra, P.V., Lima, L.N., Souza, T.C., Mazochi, V., Penna, F.J., Silva, A.M., Nicoli, J.R. and Guimarães, E.V., 2011. Pediatric functional constipation treatment with Bifidobacterium-containing yogurt: a crossover, double-blind, controlled trial. World Journal of Gastroenterology 17: 3916-3921.

Han, Y., Kim, B., Ban, J., Lee, J., Kim, B. J., Choi, B. S., Hwang, S., Ahn, K. and Kim, J., 2012. A randomized trial of Lactobacillus plantarum CJLP133 for the treatment of atopic dermatitis. Pediatric Allergy and Immunology 23: 667-673.

Hao, Q., Lu, Z., Dong, B.R., Huang, C.Q. and Wu, T., 2011. Probiotics for preventing acute upper respiratory tract infections. Cochrane Database of Systematic Reviews 9.

Hatakka, K., Blomgren, K., Pohjavuori, S., Kaijalainen, T., Poussa, T., Leinonen, M., Korpela, R. and Pitkäranta, A., 2007. Treatment of acute otitis media with probiotics in otitis-prone children a double-blind, placebo-controlled randomised study. Clinical Nutrition 26: 314-321.

Hatakka, K., Savilahti, E., Pönkä, A., Meurman, J.H., Poussa, T., Näse, L., Saxelin, M. and Korpela, R., 2001. Effect of long term consumption of probiotic milk on infections in children attending day care centres: double blind, randomised trial. British Medical Journal 322: 1327.

Hempel, S., Newberry, S., Ruelaz, A., Wang, Z., Miles, J.N.V., Suttorp, M.J., Johnsen, B., Shanman, R., Slusser, W., Fu, N., Smith, A., Roth, E., Polak, J., Motala, A., Perry, T. and Shekelle, P.G., 2011. Safety of probiotics to reduce risk and prevent or treat disease. Evidence report/technology assessment no. 200. Agency for Healthcare Research and Quality Rockville, MD, USA.

Henker, J., Laass, M.W., Blokhin, B.M., Maydannik, V.G., Bolbot, Y.K., Elze, M., Wolff, C., Schreiner, A. and Schulze, J., 2008. Probiotic Escherichia coli Nissle 1917 versus placebo for treating diarrhea of greater than 4 days duration in infants and toddlers. Pediatric Infectious Disease Journal 27: 494-499.

Heydarian, F., Kianifar, H.R., Ahanchian, H., Khakshure, A., Seyedi, J. and Moshirian, D., 2010. A comparison between traditional yogurt and probiotic yogurt in non-inflammatory acute gastroenteritis. Saudi Medical Journal 31: 280-283.

Hickey, L., Jacobs, S.E. and Garland, S.M., 2012. Probiotics in neonatology. Journal of Paediatrics and Child Health 48: 777-783.

Hill, C., Guarner, F., Reid, G., Gibson, G.R., Merenstein, D.J., Pot, B., Morelli, L., Canani, R.B., Flint, H.J., Salminen, S., Calder, P.C. and Sanders, M.E., 2014. Expert consensus document: The international scientific association for probiotics and prebiotics consensus statement on the scope and appropriate use of the term probiotic. Nature Reviews Gastroenterology and Hepatology 11: 506-514. 
Hojsak, I., Abdović, S., Szajewska, H., Milošević, M., Krznarić, Ž. and Kolaček, S., 2010a. Lactobacillus GG in the prevention of nosocomial gastrointestinal and respiratory tract infections. Pediatrics 125: e1171-e1177.

Hojsak, I., Snovak, N., Abdović, S., Szajewska, H., Mišak, Z. and Kolaček, S., 2010b. Lactobacillus GG in the prevention of gastrointestinal and respiratory tract infections in children who attend day care centers: a randomized, double-blind, placebocontrolled trial. Clinical Nutrition 29: 312-316.

Hurduc, V., Plesca, D., Dragomir, D., Sajin, M. and Vandenplas, Y., 2009. A randomized, open trial evaluating the effect of Saccharomyces boulardii on the eradication rate of Helicobacter pylori infection in children. Acta Paediatrica 98: 127-131.

Kalliomäki, M., Salminen, S., Poussa, T., Arvilommi, H. and Isolauri, E., 2003. Probiotics and prevention of atopic disease: 4-year follow-up of a randomised placebo-controlled trial. The Lancet 361: 1869-1871.

Kamada, N., Chen, G.Y., Inohara, N. and Núñez, G., 2013. Control of pathogens and pathobionts by the gut microbiota. Nature Immunology 14: 685-690.

Kerac, M., Bunn, J., Seal, A., Thindwa, M., Tomkins, A., Sadler, K., Bahwere, P. and Collins, S., 2009. Probiotics and prebiotics for severe acute malnutrition (PRONUT study): a double-blind efficacy randomised controlled trial in Malawi. The Lancet 374: 136-144.

Klein, G., 2011. Antibiotic resistance and molecular characterization of probiotic and clinical lactobacillus strains in relation to safety aspects of probiotics. Foodborne Pathogens and Disease 8: 267-281.

Ku, W.H., Lau, D.C.Y. and Huen, K.F., 2006. Other articles probiotics provoked d-lactic acidosis in short bowel syndrome: case report and literature review. Hong Kong Journal of Paediatrics 11: 246-254.

Kumar, S., Bansal, A., Chakrabarti, A. and Singhi, S., 2013. Evaluation of efficacy of probiotics in prevention of Candida colonization in a PICU - a randomized controlled trial. Critical Care Medicine 41: 565-572.

Kunz, A.N., Noel, J.M. and Fairchok, M.P., 2004. Two cases of Lactobacillus bacteremia during probiotic treatment of short gut syndrome. Journal of Pediatric Gastroenterology and Nutrition 38: 457-458.

Leyer, G.J., Li, S., Mubasher, M.E., Reifer, C. and Ouwehand, A. C., 2009. Probiotic effects on cold and influenza-like symptom incidence and duration in children. Pediatrics 124: e172-e179.

Lin, J.S., Chiu, Y.H., Lin, N.T., Chu, C.H., Huang, K.C., Liao, K.W. and Peng, K.C., 2009. Different effects of probiotic species/strains on infections in preschool children: a double-blind, randomized, controlled study. Vaccine 27: 1073-1079.

Lin, T.Y., Chen, C.J., Chen, L.K., Wen, S.H. and Jan, R.H., 2013. Effect of probiotics on allergic rhinitis in Df, Dp or dust-sensitive children: a randomized double blind controlled trial. Indian Pediatrics 50: 209-213.

Lue, K.H., Sun, H.L., Lu, K.H., Ku, M.S., Sheu, J.N., Chan, C.H. and Wang, Y.H., 2012. A trial of adding Lactobacillus johnsonii EM1 to levocetirizine for treatment of perennial allergic rhinitis in children aged 7-12 years. International Journal of Pediatric Otorhinolaryngology 76: 994-1001.
Luoto, R., Kalliomäki, M., Laitinen, K. and Isolauri, E., 2010. The impact of perinatal probiotic intervention on the development of overweight and obesity: follow-up study from birth to 10 years. International Journal of Obesity 34: 1531-1537.

Martínez-Cañavate, A., Sierra, S., Lara-Villoslada, F., Romero, J., Maldonado, J., Boza, J., Xaus, J. and Olivares, M., 2009. A probiotic dairy product containing L. gasseri CECT5714 and L. coryniformis CECT5711 induces immunological changes in children suffering from allergy. Pediatric Allergy and Immunology 20: 592-600.

Matsuda, F., Chowdhury, M.I., Saha, A., Asahara, T., Nomoto, K., Tarique, A.A., Ahmed, T., Nishibuchi, M., Cravioto, A. and Qadri, F., 2011. Evaluation of a probiotics, Bifidobacterium breve BBG01, for enhancement of immunogenicity of an oral inactivated cholera vaccine and safety: a randomized, double-blind, placebocontrolled trial in Bangladeshi children under 5 years of age. Vaccine 29: $1855-1858$.

Merenstein, D., Murphy, M., Fokar, A., Hernandez, R.K., Park, H., Nsouli, H., Sanders, E., Davis, B.A., Niborski, V., Tondu, F. and Shara, N.M., 2010. Use of a fermented dairy probiotic drink containing Lactobacillus casei (DN-114 001) to decrease the rate of illness in kids: the DRINK study A patient-oriented, double-blind, clusterrandomized, placebo-controlled, clinical trial. European Journal of Clinical Nutrition 64: 669-677.

Merenstein, D.J., Foster, J. and D’Amico, F., 2009. A randomized clinical trial measuring the influence of kefir on antibiotic-associated diarrhea: the measuring the influence of Kefir (MILK) Study. Archives of Pediatrics and Adolescent Medicine 163: 750-754.

Miele, E., Pascarella, F., Giannetti, E., Quaglietta, L., Baldassano, R.N. and Staiano, A., 2009. Effect of a probiotic preparation (VSL\#3) on induction and maintenance of remission in children with ulcerative colitis. American Journal of Gastroenterology 104: 437-443.

Miniello, V.L., Brunetti, L., Tesse, R., Natile, M., Armenio, L. and Francavilla, R., 2010. Lactobacillus reuteri modulates cytokines production in exhaled breath condensate of children with atopic dermatitis. Journal of Pediatric Gastroenterology and Nutrition 50: 573-576.

Misra, S., Sabui, T.K. and Pal, N.K., 2009. A randomized controlled trial to evaluate the efficacy of Lactobacillus GG in infantile diarrhea. Journal of Pediatrics 155: 129-132.

Munakata, S., Arakawa, C., Kohira, R., Fujita, Y., Fuchigami, T. and Mugishima, H., 2010. A case of D-lactic acid encephalopathy associated with use of probiotics. Brain and Development 32: 691-694.

Narayanappa, D., 2008. Randomized double blinded controlled trial to evaluate the efficacy and safety of Bifilac in patients with acute viral diarrhea. Indian Journal of Pediatrics 75: 709-713.

Nixon, A.F., Cunningham, S.J., Cohen, H.W. and Crain, E.F., 2012. The effect of Lactobacillus GG on acute diarrheal illness in the pediatric emergency department. Pediatric Emergency Care 28: 1048-1051. Oliva, S., Di Nardo, G., Ferrari, F., Mallardo, S., Rossi, P., Patrizi, G., Cucchiara, S. and Stronati, L., 2012. Randomised clinical trial: the effectiveness of Lactobacillus reuteri ATCC 55730 rectal enema in children with active distal ulcerative colitis. Alimentary Pharmacology and Therapeutics 35: 327-334. 
Ouwehand, A.C., Nermes, M., Collado, M.C., Rautonen, N., Salminen, S. and Isolauri, E., 2009. Specific probiotics alleviate allergic rhinitis during the birch pollen season. World Journal of Gastroenterology 15: 3261-3268.

Pan, S.J., Kuo, C.H., Lam, K.P., Chu, Y.T., Wang, W.L. and Hung, C.H., 2010. Probiotics and allergy in children - an update review. Pediatric Allergy and Immunology 21: e659-e666.

Passariello, A., Terrin, G., Cecere, G., Micillo, M., Marco, G., Di Costanzo, M., Cosenza, L., Leone, L., Nocerino, R. and Berni Canani, R., 2012. Randomised clinical trial: efficacy of a new synbiotic formulation containing Lactobacillus paracasei B21060 plus arabinogalactan and xilooligosaccharides in children with acute diarrhoea. Alimentary Pharmacology and Therapeutics 35: 782-788.

Pérez, N., Iannicelli, J.C., Girard-Bosch, C., González, S., Varea, A., Disalvo, L., Apeztequia, M., Pernas, J., Vicentin, D. and Cravero, R., 2010. Effect of probiotic supplementation on immunoglobulins, isoagglutinins and antibody response in children of low socioeconomic status. European Journal of Nutrition 49: 173-179.

Reddy, V.S., Patole, S.K. and Rao, S., 2013. Role of probiotics in short bowel syndrome in infants and children - a systematic review. Nutrients 5: 679-699.

Rerksuppaphol, S. and Rerksuppaphol, L., 2010. Lactobacillus acidophilus and Bifidobacterium bifidum stored at ambient temperature are effective in the treatment of acute diarrhoea. Annals of Tropical Paediatrics 30: 299-304.

Rerksuppaphol, S. and Rerksuppaphol, L., 2012. Randomized controlled trial of probiotics to reduce common cold in schoolchildren. Pediatrics International 54: 682-687.

Riaz, M., Alam, S., Malik, A. and Ali, S.M., 2012. Efficacy and safety of Saccharomyces boulardii in acute childhood diarrhea: a double blind randomised controlled trial. Indian Journal of Pediatrics 79: 478-482.

Ruszczyński, M., Radzikowski, A. and Szajewska, H., 2008. Clinical trial: effectiveness of Lactobacillus rhamnosus (strains E/N, Oxy and Pen) in the prevention of antibiotic-associated diarrhoea in children. Alimentary Pharmacology and Therapeutics 28: 154-161.

Saavedra, J.M., Abi-Hanna, A., Moore, N. and Yolken, R.H., 2004. Long-term consumption of infant formulas containing live probiotic bacteria: tolerance and safety. The American Journal of Clinical Nutrition 79: 261-267.

Salminen, M.K., Tynkkynen, S., Rautelin, H., Saxelin, M., Vaara, M., Ruutu, P., Sarna, S., Valtonen, V. and Järvinen, A., 2002. Lactobacillus bacteremia during a rapid increase in probiotic use of Lactobacillus rhamnosus GG in Finland. Clinical Infectious Diseases 35: 1155-1160.

Salminen, S., Von Wright, A., Morelli, L., Marteau, P., Brassart, D., De Vos, W.M., Fondén, R., Saxelin, M., Collins, K., Mogensen, G., Birkeland, S.E. and Mattila-Sandholm, T., 1998. Demonstration of safety of probiotics - a review. International Journal of Food Microbiology 44: 93-106.

Sanders, M.E., Guarner, F., Guerrant, R., Holt, P.R., Quigley, E.M., Sartor, R.B., Sherman, P.M. and Mayer, E.A., 2013. An update on the use and investigation of probiotics in health and disease. Gut 62: 787-796.
Sazawal, S., Dhingra, U., Hiremath, G., Sarkar, A., Dhingra, P., Dutta, A., Verma, P., Menon, V.P. and Black, R.E., 2010. Prebiotic and probiotic fortified milk in prevention of morbidities among children: community-based, randomized, double-blind, controlled trial. PLoS ONE 5: e12164.

Sentongo, T.A., Cohran, V., Korff, S., Sullivan, C., Iyer, K. and Zheng, X., 2008. Intestinal permeability and effects of Lactobacillus rhamnosus therapy in children with short bowel syndrome. Journal of Pediatric Gastroenterology and Nutrition 46: 41-47.

Shafiei, A., Moin, M., Pourpak, Z., Gharagozlou, M., Aghamohamadi, A. and Sajedi, V., 2011. Synbiotics could not reduce the scoring of childhood atopic dermatitis (SCORAD): a randomized double blind placebo-controlled trial. Iranian Journal of Allergy, Asthma and Immunology 10: 21-28.

Simakachorn, N., Bibiloni, R., Yimyaem, P., Tongpenyai, Y., Varavithaya, W., Grathwohl, D., Reuteler, G., Maire, J.C., Blum, S., Steenhout, P., Benyacoub, J. and Schiffrin, E.J., 2011. Tolerance, safety, and effect on the faecal microbiota of an enteral formula supplemented with pre-and probiotics in critically ill children. Journal of Pediatric Gastroenterology and Nutrition 53: 174-181.

Singh, R., Damle, S.G. and Chawla, A., 2011. Salivary mutans streptococci and lactobacilli modulations in young children on consumption of probiotic ice-cream containing Bifidobacterium lactis Bb12 and Lactobacillus acidophilus La5. Acta Odontologica Scandinavica 69: 389-394.

Skovbjerg, S., Roos, K., Holm, S.E., Håkansson, E.G., Nowrouzian, F., Ivarsson, M., Adlerberth, I. and Wold, A.E., 2009. Spray bacteriotherapy decreases middle ear fluid in children with secretory otitis media. Archives of Disease in Childhood 94: 92-98.

Stecksén-Blicks, C., Sjöström, I. and Twetman, S., 2009. Effect of long-term consumption of milk supplemented with probiotic lactobacilli and fluoride on dental caries and general health in preschool children: a cluster-randomized study. Caries Research 43: 374-381.

Strachan, D.P., 1989. Hay fever, hygiene, and household size. British Medical Journal 299: 1259-1260.

Sur, D., Manna, B., Niyogi, S.K., Ramamurthy, T., Palit, A., Nomoto, K., Takahashi, T., Shima, T., Tsuji, H., Kurawaka, T. Takeda, Y., Nair, G.B. and Bhattacharya, S.K., 2011. Role of probiotic in preventing acute diarrhoea in children: a community-based, randomized, doubleblind placebo-controlled field trial in an urban slum. Epidemiology and Infection 139: 919-926.

Surono, I.S., Koestomo, F.P., Novitasari, N. and Zakaria, F.R., 2011. Novel probiotic Enterococcus faecium IS-27526 supplementation increased total salivary sIgA level and bodyweight of pre-school children: a pilot study. Anaerobe 17: 496-500.

Szachta, P., Ignys, I. and Cichy, W., 2011. An evaluation of the ability of the probiotic strain Lactobacillus rhamnosus GG to eliminate the gastrointestinal carrier state of vancomycin-resistant enterococci in colonized children. Journal of Clinical Gastroenterology 45: 872-877.

Szajewska, H. and Skórka, A., 2009. Saccharomyces boulardii for treating acute gastroenteritis in children: updated meta-analysis of randomized controlled trials. Alimentary Pharmacology and Therapeutics 30: 960-961. 
Szajewska, H., Albrecht, P. and Topczewska-Cabanek, A., 2009. Randomized, double-blind, placebo-controlled trial: effect of lactobacillus GG supplementation on Helicobacter pylori eradication rates and side effects during treatment in children. Journal of Pediatric Gastroenterology and Nutrition 48: 431-436.

Szymański, H., Armańska, M., Kowalska-Duplaga, K. and Szajewska, H., 2008. Bifidobacterium longum PL03, Lactobacillus rhamnosus KL53A, and Lactobacillus plantarum PL02 in the prevention of antibiotic-associated diarrhea in children: a randomized controlled pilot trial. Digestion 78: 13-17.

Tabbers, M.M., Chmielewska, A., Roseboom, M.G., Crastes, N., Perrin, C., Reitsma, J.B., Norbruis, O., Szajewska, H. and Benninga, M.A., 2011. Fermented milk containing Bifidobacterium lactis DN-173 010 in childhood constipation: a randomized, double-blind, controlled trial. Pediatrics 127: e1392-e1399.

Tan, M., Zhu, J.C., Du, J., Zhang, L.M. and Yin, H.H., 2011. Effects of probiotics on serum levels of Th1/Th2 cytokine and clinical outcomes in severe traumatic brain-injured patients: a prospective randomized pilot study. Critical Care 15: R290.

Tolone, S., Pellino, V., Vitaliti, G. and Tolone, C., 2012. Evaluation of Helicobacter Pylori eradication in pediatric patients by triple therapy plus lactoferrin and probiotics compared to triple therapy alone. Italian Journal of Pediatrics 38: 1-5.

Torii, S., Torii, A., Itoh, K., Urisu, A., Terada, A., Fujisawa, T., Yamada, K., Suzuki, H., Ishida, Y., Nakamura, F., Kanzato, H., Sawada, D., Nonaka, A., Hatanaka, M. and Fujiwara, S., 2011. Effects of oral administration of Lactobacillus acidophilus L-92 on the symptoms and serum markers of atopic dermatitis in children. International Archives of Allergy and Immunology 154: 236-245.

Vajro, P., Mandato, C., Licenziati, M.R., Franzese, A., Vitale, D.F., Lenta, S., Caropreso, M., Vallone, G. and Meli, R., 2011. Effects of Lactobacillus rhamnosus strain GG in pediatric obesity-related liver disease. Journal of Pediatric Gastroenterology and Nutrition 52: 740-743.

Van den Nieuwboer, M., Brummer, R.J., Guarner, F., Morelli, L., Cabana, M. and Claassen, E., 2015. The administration of probiotics and synbiotics in immune compromised adults: is it safe? Beneficial Microbes 6: 3-17.
Van den Nieuwboer, M., Claassen, E., Morelli, L., Guarner, F. and Brummer, R.J., 2014. Probiotic and synbiotic safety in infants under two years of age. Beneficial Microbes 5: 45-60.

Van Der Aa, L.B., Heymans, H.S., Van Aalderen, W. and Sprikkelman, A.B., 2010. Probiotics and prebiotics in atopic dermatitis: review of the theoretical background and clinical evidence. Pediatric Allergy and Immunology 21: e355-e367.

Vandenplas, Y. and De Hert, S.G., 2011. Randomised clinical trial: the synbiotic food supplement Probiotical vs. placebo for acute gastroenteritis in children. Alimentary Pharmacology and Therapeutics 34: 862-867.

Vyas, U. and Ranganathan, N., 2012. Probiotics, prebiotics, and synbiotics: gut and beyond. Gastroenterology Research and Practice 2012: article ID 872716.

Wada, M., Nagata, S., Saito, M., Shimizu, T., Yamashiro, Y., Matsuki, T., Asahara, T. and Nomoto, K., 2010. Effects of the enteral administration of Bifidobacterium breve on patients undergoing chemotherapy for pediatric malignancies. Supportive Care in Cancer 18: 751-759.

Wanke, M. and Szajewska, H., 2012. Lack of an Effect of Lactobacillus reuteri DSM 17938 in preventing nosocomial diarrhea in children: a randomized, double-blind, placebo-controlled trial. Journal of Paediatrics 161: 40-43.

Weichert, S., Schroten, H. and Adam, R., 2012. The role of prebiotics and probiotics in prevention and treatment of childhood infectious diseases. Pediatric Infectious Disease Journal 31: 859-862.

Woo, S.I., Kim, J.Y., Lee, Y.J., Kim, N.S. and Hahn, Y.S., 2010. Effect of Lactobacillus sakei supplementation in children with atopic eczemadermatitis syndrome. Annals of Allergy, Asthma and Immunology 104: 343-348.

Wu, K.G., Li, T.H. and Peng, H.J., 2012. Lactobacillus salivarius plus fructo-oligosaccharide is superior to fructo-oligosaccharide alone for treating children with moderate to severe atopic dermatitis: a double-blind, randomized, clinical trial of efficacy and safety. British Journal of Dermatology 166: 129-136. 